\title{
Cost and consequences of using $7.1 \%$ chlorhexidine gel for newborn umbilical cord care in Kenya
}

Lecia Brown ( $\sim$ Lecia.x.brown@gsk.com )

Clinical Development, GSK

Alan Martin

Value Evidence and Outcomes, GSK

Christopher Were

Medical Department, GSK

Nandita Biswas

Biostatistics, GSK

Alexander Liakos

Global Health, GSK

Elena DeAngelis

Global Health, GSK

Lee Evitt

ViiV Healthcare

\section{Research Article}

Keywords: Chlorhexidine, dry cord care, Kenya, omphalitis, cost-consequence

Posted Date: April 6th, 2021

DOl: https://doi.org/10.21203/rs.3.rs-362323/v1

License: (c) (i) This work is licensed under a Creative Commons Attribution 4.0 International License. Read Full License

Version of Record: A version of this preprint was published at BMC Health Services Research on November 19th, 2021. See the published version at https://doi.org/10.1186/s12913-021-06971-7. 


\section{Abstract}

Background: Umbilical-cord infection (omphalitis) is a major cause of neonatal mortality in Kenya. Chlorhexidine $7.1 \%$ digluconate gel, (CHX), delivering $4 \%$ chlorhexidine was identified as a life-saving commodity for newborn cord care by the United Nations and is included on the World Health Organization and Kenyan Essential Medicines Lists.

Methods: We employed a cost-consequence model to assess resource saving and breakeven price of implementing $\mathrm{CHX}$ for neonatal umbilical cord care versus dry cord care (DCC) in a Kenyan birth cohort. Firstly, the number of omphalitis cases and cases avoided by healthcare sector were estimated. Economic outcomes associated with omphalitis cases avoided were then determined, including direct, indirect and total cost of care associated with omphalitis, resource use (outpatient visits and bed days) and societal impact (caregiver workdays lost). Treatment effect inputs were calculated from a Cochrane meta-analysis of randomised clinical trials (RCTs) (base case) and 2 other RCTs. Costs and other inputs were sourced from the literature and supplemented by expert clinical opinion/informed inputs, making assumptions as necessary.

Reports: The model estimated that, over 1 year, 23,000 omphalitis cases per 500,000 births could be avoided through CHX application versus DCC, circumventing $\sim 13,000$ outpatient visits, $\sim 43,000$ bed days and preserving $\sim 114,000$ workdays. CHX was associated with annual direct cost savings of $\sim 590,000$ US dollars (USD) versus DCC (not including drug-acquisition cost), increasing to 2.5 million USD after including indirect costs (productivity, notional salary loss). The most-influential model parameter was relative risk of omphalitis with $\mathrm{CHX}$ versus DCC. Breakeven analysis identified a budget-neutral price for $\mathrm{CHX}$ use of $1.18 \mathrm{USD} /$ course when accounting for direct cost savings only, and of $5.43 \mathrm{USD} /$ course when also including indirect cost savings. The estimated breakeven price was robust to parameter input changes. DCC does not necessarily represent standard of care in Kenya; other, potentially harmful, approaches may be used, meaning cost savings may be understated.

Conclusions: Estimated healthcare cost savings and potential health benefits provide compelling evidence to implement $\mathrm{CHX}$ for umbilical cord care in Kenya. We encourage comprehensive data collection to make future models and estimates of the impacts of upscaling $\mathrm{CHX}$ use more robust.

\section{Background}

Umbilical-cord infections (omphalitis) are a major cause of neonatal mortality in low- and middle-income countries [1], where the newly cut umbilical cord can be an entry point for bacteria, causing newborn sepsis and death [2]. The causes of neonatal infection may be related to cord-care choices postpartum, including cultural practices of applying traditional substances, such as cow dung or ash, that may be harmful to the umbilical cord as part of postnatal care [3, 4]. Cord care also includes the use of gentian violet, silver sulphadiazine, topical antibiotics, and methylated and surgical spirits [3-5]. 
In 2012, the United Nations (UN) identified chlorhexidine (CHX), an antiseptic agent with topical antibacterial activity, as a life-saving commodity for newborn cord care [6]. The UN called for pharmaceutical manufacturers to supply high-quality, affordable $\mathrm{CHX}$ that, if accessed more widely, could save 422,000 neonatal lives over 5 years [6]. In 2013, the World Health Organization (WHO) added CHX to its Model List of Essential Medicines for Children, as a gel of 7.1\% (digluconate) delivering 4\% CHX [7]. That year, the WHO also issued guidelines on umbilical cord care, based on evidence of efficacy and safety from three large community-based randomised clinical trials (RCTs) in low- and middle-income Asian countries [8-10]. These guidelines recommend daily application of $4 \% \mathrm{CHX}$ (during the first week of life) for in home-birth settings with high neonatal mortality rates, and where $\mathrm{CHX}$ may replace potentially harmful traditional approaches to cord care [11]. In response to the UN call, and in line with the WHO guidelines, GlaxoSmithKline developed a $\mathrm{CHX}$ digluconate $7.1 \% \mathrm{w} / \mathrm{w}$ gel, equivalent to $4 \% \mathrm{w} / \mathrm{w} \mathrm{CHX}$, in collaboration with Save the Children [12]. This was produced in single-use sachets. As part of the collaboration, a managed access programme investigated the use of $\mathrm{CHX}$ for newborn umbilical cord care across 21 healthcare facilities in Bungoma County, Kenya. Feedback from healthcare providers and mothers indicated positive outcomes in terms of reduced newborn infections and ease of use [13]. There is locally manufactured multi-application $\mathrm{CHX}$ available, supplied in a bottle or tube.

In higher-income countries, keeping the cord clean and dry - 'dry cord care' (DCC) is sufficient under most circumstances [14]. CHX is associated with reduced infection and omphalitis rates compared with DCC in studies conducted in low-resource settings [15-17]; therefore, the use of $\mathrm{CHX}$ could lead to reductions in subsequent healthcare costs. However, DCC is not necessarily the standard of care in low- and middleincome countries, where mothers may frequently use a potentially harmful product on the cord [3-5]. Despite recommendations for use from international organisations, there is limited analysis on the financial implications of the introduction and national scale-up of $\mathrm{CHX}$ use for neonatal cord care. Generation of such data could help inform financial decision-making.

However, there are concerns regarding the safety and effectiveness of $\mathrm{CHX}$. The WHO issued a $\mathrm{CHX}$ safety alert in 2019 following at least 40 recorded incidents, across nine sub-Saharan countries, of CHX misuse in the eye when mistaken for eye drops and ointments, leading to injury and, in some cases, blindness [18]. Additionally, data from two clinical trials in African countries were more equivocal in terms of impact on mortality of $\mathrm{CHX}$ versus DCC, than the previously mentioned Asian studies $[16,17]$.

Kenya, located in East Africa, has a higher neonatal mortality rate than the average globally and of low- to middle-income countries, at 20 deaths per 1000 live births [19]. Neonatal care is predominantly provided by the public sector, but also through private and faith-based organisations (FBO) [20]. In 2014, the Kenyan Ministry of Health began to develop national guidelines on newborn cord care and the use of $\mathrm{CHX}$. This led to the inclusion of CHX in the Kenyan Essential Medicines List [21]. Given the WHO recommendations and national clinical guidelines supporting the use of $\mathrm{CHX}$ in home-birth settings with high neonatal mortality rates, understanding the economic consequences of upscaling the use of $\mathrm{CHX}$ may be helpful in supporting investment decisions. These analyses are viewed as relevant for Kenya because there is variation in neonatal mortality rates between counties [22], and despite the move 
towards scale-up of $\mathrm{CHX}$ as part of routine postnatal care, a prominent proportion of neonates still receive improper cord-care hygiene [4]. Evidence suggests that supply of locally manufactured $\mathrm{CHX}$ is still fragmented and barriers to widespread use of $\mathrm{CHX}$ persist [13].

The goal of this preliminary study was to provide initial evidence of the financial and clinical implications associated with the use of $\mathrm{CHX}$, through a cost-consequence analysis assessing the implementation of $\mathrm{CHX}$ gel for neonatal umbilical cord care in Kenya. It is hoped that this will be used as the foundation for future studies that will utilise more extensive datasets and additional sources to reduce any uncertainty surrounding the model outcomes.

\section{Methods}

\section{Overview}

This cost-consequence analysis assessed clinical and economic outcomes for $\mathrm{CHX}$ gel compared with DCC for neonatal umbilical cord care in Kenya, from both healthcare system and societal perspectives. Clinical outcomes were number of cases and number of cases avoided by sector. Economic outcomes were direct, indirect and total cost of care for omphalitis, resource use (number of bed days and outpatient visits) and societal impact (workdays lost). Breakeven analysis was performed to ascertain the price of $\mathrm{CHX}$ that would lead to a net-neutral budget outcome.

\section{Model structure}

The model is a spreadsheet calculation (Microsoft Excel) analysing the frequency of omphalitis cases and financial implications (cost-consequence) associated with implementing either DCC or CHX as cord care strategies in neonates (Figure 1). For each strategy, the number of cases of omphalitis is calculated, followed by the overall cost of the infection accounting for the sector providing omphalitis treatment (private, public, FBO) and the setting of care (inpatient or outpatient).

\section{Model inputs}

Key model inputs are summarised below; further details are provided in Supplementary Tables 1-6.

Patient population: Birth cohort of 500,000 in Kenya for 1 year, with an average birth weight of $3.3 \mathrm{~kg}$ [23].

Clinical efficacy: The inputs used to determine the clinical efficacy of DCC and CHX for the base case analysis were taken from a Cochrane systematic literature review based on three RCTs conducted in Asian countries [8-10, 24]. The Cochrane review provides the largest pool and most robust data for clinical efficacy and was used by the WHO to support its recommendation for use of CHX versus DCC [11, 24]. Additionally, two RCTs, conducted in African countries, were used to determine the most relevant and applicable efficacy inputs to be used $[16,17]$. Further justification for the use of this literature is shown in 
Supplementary Table 7. Relative risk of omphalitis - due to limitations on data reporting within publications, an overall relative risk for omphalitis for $\mathrm{CHX}$ versus DCC could not be calculated, and for the base case was assumed to be equivalent to the relative risk reported in the Cochrane review for the "redness extending to the skin" categorisation (RR:0.73). This is a conservative effect size when compared with that reported for other severity categories [24]. Omphalitis case inputs - the inputs to determine the number of cases of omphalitis calculated in the model were taken from the efficacy of DCC and $\mathrm{CHX}$ from the Cochrane review comparing the two cord care approaches [24] (Supplementary Table 1). As an overall incidence rate of omphalitis was not reported in the Cochrane review, a weighted average was calculated of incidence rates of all severities of omphalitis associated with the DCC intervention arm from the three randomised control trials included in the Cochrane review [24].

Cord care treatment costs: The aim of the present analysis was to determine the breakeven budgetneutral price of $\mathrm{CHX}$, therefore, the acquisition cost has not been included. As there is a generic local manufacturer in Kenya, it was assumed that all $\mathrm{CHX}$ was locally manufactured. For locally manufactured $\mathrm{CHX}$, which is delivered in a multiple-application formulation, the number of days of treatment in each tube becoming wastage is also assumed. DCC was assumed to be associated with a zero cost. Cost inputs were converted from Kenyan shillings (KSH) to USD at an exchange rate of $100.83 \mathrm{KSH}$ per 1 USD (Statistics, 2018) (Supplementary Table 2).

Proportion of patients per sector: No data could be identified in the literature; therefore, assumptions based on clinical opinion were used for the proportion of omphalitis cases treated in different sectors (Supplementary Table 1).

Inpatient and outpatient resource use and costs: The proportion of patients treated in each setting was based on clinical opinion. Costs for inpatient days and outpatient visits were populated drawing on the costs for Kenya provided in WHO-CHOICE 2008 [25], inflated to 2019 cost using the annual Kenya Consumer Price Index [26]. Costs accounted for personnel, capital and (for inpatient care) food [25, 26]. To reflect the structure of Kenya's outpatient facilities, health centers (no beds), health centers (with beds) and primary level hospitals were averaged to provide an input for primary level care costs. Outpatient care was averaged across primary level, secondary level and teaching hospitals, weighted by the proportion of patients treated in each setting (Supplementary Table 2).

Medication costs: These model inputs were based on WHO guidelines, Kenya Paediatric guidelines and expert clinical opinion and assume the medication used and duration of treatment for omphalitis is influenced by sector and setting of care [4,27] (Supplementary Tables 2 and 3 ). Costs were calculated using the cost of the medication by pack/vial, dosage prescribed and treatment length (in days).

Non-medication costs: Laboratory test costs associated with treating omphalitis were sourced from the literature [28], with FBO sector laboratory costs assumed to be one-third of private sector costs. To reflect the reality of the clinical environment, other non-medication costs were also included based on clinical opinion. This included the number and cost of consumables, and number of laboratory tests associated with treating omphalitis, both assumed to be equivalent across sectors (Supplementary Tables $\mathbf{4}$ and 5). 
Societal factors and productivity: To understand the caregiver/family impact of caring for a child with omphalitis in Kenya, the model also estimated the impact on productivity and private financial losses based on the average gross salary and workdays lost through caring for a neonate with omphalitis.

\section{(Supplementary Table 6).}

\section{Model assumptions}

Assumptions relating to incidence rates of omphalitis with DCC, comparative efficacy of CHX versus DCC, medication use and productivity loss are listed in Table 1. Further details on model assumptions are included in the Supplementary Methods.

\section{Analysis}

For the primary analysis a healthcare system perspective was taken to estimate the costs and benefits of implementing $\mathrm{CHX}$ for the Ministry of Health in Kenya or relevant healthcare provider, both overall and by sector (private, public or FBO) and setting of care (inpatient or outpatient). This included medication cost and costs associated with healthcare resource use in the treatment of omphalitis. In addition, a scenario with a societal perspective on the introduction of $\mathrm{CHX}$ was also analysed. This included the impact on productivity and workdays lost associated with time off work due to the consequences of different cord care interventions. The time horizon was 1 year, so no discounting was applied. Input values for the base case (direct costs only) and scenario (which also included indirect costs) are described above and in Supplementary Tables 1-6.

The analysis aimed to determine the impact on the costs of omphalitis treatment. Therefore, the cost of $\mathrm{CHX}$ was not included. Instead, cost of $\mathrm{CHX}$ was addressed as part of the breakeven analysis described below.

The analysis compared two treatment approaches: DCC (assumed to be standard of care) and CHX application (Figure 1). Patients were assumed to receive either CHX or DCC; however, in many low- and middle-income countries, mothers often choose to apply other remedies; such as methylated spirits and ash on the cord $[3,4]$. As this analysis used data that reflects the WHO guidelines on recommended cord care [29] and the available clinical trial data $[16,17,24]$, it does not include the use of other substances; therefore, it represents a conservative analysis. Neonatal mortality was not included in the model, only the effect of $\mathrm{CHX}$ on rates of omphalitis.

\section{Breakeven analysis}

Breakeven analysis was performed to ascertain the price of $\mathrm{CHX}$ that would lead to a net-neutral budget outcome, where any $\mathrm{CHX}$ price below this would allow savings from reducing omphalitis cases to be realised. This analysis was conducted from both perspectives, considering direct cost savings only and both direct and indirect cost savings. 


\section{One-way sensitivity analysis}

A one-way sensitivity analysis was programmed to evaluate the robustness and sensitivity of results to changes in parameter values, to identify those parameters with the greatest influence on model outcomes. Upper and lower parameter values were based on ranges informed by plausible variation $( \pm 20 \%)$ and are shown in Supplementary Tables 1-6.

\section{Results}

\section{Clinical outcomes}

\section{Cases of omphalitis by sector}

The model estimated that in a birth cohort of 500,000 newborns in Kenya, with DCC as routine cord care for newborns, approximately 85,000 omphalitis cases would occur, with 51,000 treated in the public sector, 15,000 in both the private and FBO systems, and 4000 untreated. Of these, 48,000 cases would be seen as outpatients and 32,000 as inpatients. With $\mathrm{CHX}$, approximately 62,000 omphalitis cases would occur, with 37,000 treated in the public sector, 11,000 in both the private and FBO systems and 3000 untreated. Of these, 35,000 cases would be seen as outpatients and 24,000 as inpatients. (Figure 2).

\section{Cases of omphalitis avoided}

With base case inputs (Supplementary Tables 1-6), the cost-consequence model estimated that $\mathrm{CHX}$ introduction to a birth cohort of 500,000 newborns in Kenya may lead to the avoidance of approximately 23,000 omphalitis cases compared with DCC (Figure 2). The scale of these reductions was consistent across the three treatment sectors, with $\mathrm{CHX}$ reducing incidence of omphalitis by approximately 14,000 cases in the public setting and 4000 cases in the private and FBO settings. Across treatment sectors, the model estimated that the use of CHX over DCC can avoid approximately 9000 omphalitis cases in the inpatient setting and approximately 13,000 cases of omphalitis in the outpatient setting.

\section{Economic outcomes}

\section{Costs}

Due to the modelling assumptions, DCC was associated with zero acquisition costs. Acquisition cost of $\mathrm{CHX}$ was not included in the analysis of direct costs (i.e. monetised healthcare resource use only, as the analysis looked to estimate the breakeven cost for $\mathrm{CHX}$ ). $\mathrm{CHX}$ usage led to a decreased cost of care for omphalitis of approximately 590,000 USD compared with DCC (Table 2). Medication, hospitalisation, outpatient and non-medication costs associated with omphalitis were all lower with the use of $\mathrm{CHX}$ 
compared with DCC (Table 2). The most significant subcategory of direct cost savings was hospitalisations, which contributed almost 400,000 USD of savings. When including indirect costs associated with salary loss, the estimated total cost savings increased to over 2.5 million USD when using CHX over DCC.

\section{Breakeven analysis}

Taken from the healthcare system perspective, when considering direct costs only, the estimated breakeven price of $\mathrm{CHX}$ when used in place of DCC was 1.18 USD per course. Therefore, use of $\mathrm{CHX}$ at any price below this could lead to direct cost savings to the healthcare system. When considering both direct and indirect costs (from a societal perspective) the breakeven price of CHX became 5.43 USD per course (Figure 3 ). The acquisition cost of $\mathrm{CHX}$ was not included in this analysis.

\section{Resource use and societal impact}

It was estimated that approximately 13,000 outpatient visits could be avoided and approximately 43,000 bed days saved through use of CHX over DCC. When assessing the societal impact, approximately 114,000 fewer workdays were lost due to caring for a neonate with omphalitis for CHX versus DCC (Table 3).

\section{Impact of changing parameter values on cost of $\mathrm{CHX}$ versus DCC}

Based on the one-way sensitivity analysis, the 14 most influential parameters are presented in Figure 4, when assessing direct costs only, and Figure 5, when assessing both direct and indirect costs. The acquisition cost of $\mathrm{CHX}$ was not included in this analysis. Overall, the reduction in total healthcare spend on omphalitis treatment with $\mathrm{CHX}$ versus $\mathrm{DCC}$ is robust to changes in parameter values, remaining close to a 590,000 USD reduction in the base case for most parameters for direct costs; the breakeven price remains close to the base case of approximately 1.18 USD, following changes in most parameters (Figure 4). The most influential parameter was the relative risk of omphalitis with $\mathrm{CHX}$ versus DCC for both direct and indirect costs. There are still cost savings even after the relative efficacy was reduced by $20 \%$ (relative risk changed from 0.73 to 0.88 ), when considering direct costs only (Figure 4) and also if indirect costs are included (Figure 5). Other influential parameters for direct costs included wastage of antibiotic tablets (penicillin) for omphalitis treatment and omphalitis incidence with DCC. When indirect costs are included, average workdays lost per case and average annual income also become influential, since these determine the extent of the societal cost due to time off work from omphalitis cases.

\section{Discussion}


$\mathrm{CHX}$, identified as a life-saving commodity by the UN, is included in the Kenya Essential Medicines List and neonatal care guidelines. The preliminary analysis presented here provides an initial assessment of the financial implications associated with $\mathrm{CHX}$ implementation for cord care in a birth cohort in Kenya.

Using the best available evidence from published literature, supported by expert clinical opinion, the results of this model suggest that the use of $\mathrm{CHX}$ versus DCC can lead to a reduced number of omphalitis cases in neonates and therefore provides cost savings when considering the cost of cord care and omphalitis treatment. It was estimated that introducing $\mathrm{CHX}$ use in a birth cohort of 500,000 newborns in Kenya could lead to the avoidance of 23,000 omphalitis cases compared with DCC, with reductions consistent across treatment sectors. Although neonatal mortality was not included in the model, this reduction in omphalitis cases with $\mathrm{CHX}$ use is expected to lead to improved clinical outcomes in neonatal cord care, and ultimately, a reduction in neonatal deaths.

The cost savings associated with CHX use versus DCC may be understated as the birth cohort of 500,000 used in this analysis is approximately 2.6-fold lower than the projected births in Kenya, based on data for 2014 [30]. As hospitalisations were identified as the most substantial subcategory of direct cost savings, implementation of $\mathrm{CHX}$ treatment could lead to extensive future savings in government healthcare facilities, which have been identified as important distribution points for $\mathrm{CHX}$ [31]. After accounting for the savings associated with the healthcare system's direct resource use, the cost of $\mathrm{CHX}$ at which its use becomes budget neutral (i.e. off-setting the savings through resource use reduction) was 1.18 USD; CHX use instead of DCC at a price up to this threshold was found to lead to a direct cost saving to the healthcare system (without accounting for costs associated with purchasing other cord care products, such as methylated spirits).

These data provide supporting evidence of the value that $\mathrm{CHX}$ could bring to the healthcare system for healthcare providers and manufacturers, which can be used to guide fair pricing regulation and policy [32]. Of note, the aforementioned budget neutrality does not take into account the potential social and health-related quality of life benefits that would likely come from reducing rates of omphalitis and improving neonatal care, and this should also be factored into healthcare decision-making. One-way sensitivity analysis findings suggested that overall, the monetised resource use reduction in total healthcare spend in Kenya with $\mathrm{CHX}$ versus DCC is robust to changes in a wide range of parameters and therefore, so is the breakeven price of $\mathrm{CHX}$.

As this study represents a preliminary analysis, there are some limitations to consider. First, there was a paucity of data available for many of the model inputs, so assumptions and expert clinical opinion were used. These include assumptions on $\mathrm{CHX}$ treatment duration, that it would be properly administered, and its real-world effectiveness. However, the impact of this may not be as large as expected; as described above, the cost saving with $\mathrm{CHX}$ was robust to changes in the parameters based on assumptions guided by clinical opinion. Second, despite DCC representing the standard of care in this model, it is not viewed as being realistically representative of the standard of care in Kenya, where substances such as gentian violet, silver sulphadiazine, topical antibiotics and surgical methylated spirits, or even potentially more 
harmful substances such as ash or saliva, are often used [3-5]. Therefore, the model likely provides a conservative estimate of resource use and cost savings, as $\mathrm{CHX}$ gel was compared with DCC rather than the application of these other substances. This may mean that the cost savings were underestimated in this model. Third, indirect costs may have been overestimated in this model due to assumptions about productivity loss and standardised salary. Kenya has many workers who are paid daily rather than receiving a salary, and similarly, a proportion of parents may not be employed or may have chosen to take planned absence from work to care for their newborn, irrespective of whether they have omphalitis or not. All of these may contribute to an overestimation of the impact on productivity and therefore, this model provides a notional estimate of indirect costs.

Healthcare system decision-makers need also consider some wider issues around the implementation of $\mathrm{CHX}$. In relation to safety, both liquid and gel formulations have been associated with eye injuries when mistaken for eye drops and ointments, leading the WHO to warn all those involved in distributing and administering $\mathrm{CHX}$ to take appropriate steps to ensure its correct use [18]. National budget allocation for $\mathrm{CHX}$ implementation must also be provided for, as part of the UN recommendation/call to action [6].

It is hoped that the potential cost savings highlighted in this preliminary cost-consequence model will encourage more comprehensive data generation to address the current information gaps around $\mathrm{CHX}$ effectiveness, epidemiological data and patterns of omphalitis care, thus making future models more robust and inform health systems further. To obtain a more holistic picture of the health impact of different cord care strategies it would be of interest to include humanistic factors such as health-related quality of life; and the effect of the stress and anxiety caused by omphalitis on parents and carers.

\section{Conclusions}

These preliminary findings, based on the best available evidence, indicate that use of one course of $\mathrm{CHX}$ priced up to the breakeven price of 1.18 USD for direct costs only and 5.43 USD when including indirect costs could lead to cost savings compared with DCC, while also improving clinical outcomes in neonatal cord care. Reduction in healthcare costs and the breakeven price were robust to input parameter changes. Due to the conservative nature of the model, cost savings, and therefore the budget-neutral price, may have been underestimated and further analyses are encouraged. This analysis may be useful for policy makers and payers making investment decisions around $\mathrm{CHX}$ use for cord care in Kenya and may serve as a starting point for similar discussion in other health systems.

\section{List Of Abbreviations}

$\mathrm{CHX}$, chlorhexidine; DCC, dry cord care; FBO, faith-based organisation; $\mathrm{KSH}$, Kenya shillings; UN, United Nations; USD, US dollar; WHO, World health Organization.

\section{Declarations}




\section{Ethics approval and consent to participate}

Not applicable

\section{Consent for publication}

Not applicable

\section{Availability of data and materials}

The datasets used and/or analysed during the current study are available from the corresponding author on reasonable request.

\section{Competing interests}

LB, AM, CW, NB, AL and ED are employees of GlaxoSmithKline (GSK), LE is an employee of Viiv healthcare. All authors hold stocks/shares in GSK. GSK was involved in the study design, data collection and analysis, decision to publish, and preparation of the manuscript.

\section{Funding}

This study was funded by GSK.

\section{Authors' contributions}

$L B, A M, C W, N B, A L$ and $E D$ were involved in the conception and design of the study. $L B, A M, C W, N B, E D$ and LE were involved in the data analysis and acquisition. All authors contributed to the review of the manuscript and approved the submitted version.

\section{Acknowledgements}

Editorial support in the form of development of the initial draft, collating author comment, assembling tables and figures, copyediting and referencing was provided by Alistair Jones, PhD, and Robert Bloxham of Fishawack Indicia Ltd of Fishawack Health UK, and funded by GSK. The authors would like to acknowledge and thank Lynn Kanyuuru and Dr Osman Warfa for their valuable contributions to this study.

\section{References}


1. Karumbi J, Mulaku M, Aluvaala J, English M, Opiyo N: Topical umbilical cord care for prevention of infection and neonatal mortality. The Pediatric infectious disease journal 2013, 32(1):78-83.

2. Coffey PS, Brown SC: Umbilical cord-care practices in low- and middle-income countries: a systematic review. BMC Pregnancy Childbirth 2017, 17(1):68.

3. Abegunde D, Orobaton N, Beal K, Bassi A, Bamidele M, Akomolafe T, Ohanyido F, Umar-Farouk O, Danladi Sa: Trends in newborn umbilical cord care practices in Sokoto and Bauchi States of Nigeria: the where, who, how, what and the ubiquitous role of traditional birth attendants: a lot quality assurance sampling survey. BMC Pregnancy and Childbirth 2017, 17(1):368.

4. Moraa PK, Mweu MM, Njoroge PK: Association between umbilical cord hygiene and neonatal sepsis among neonates presenting to a primary care facility in Nairobi County, Kenya: a case-control study. F1000Research 2019, 8:920-920.

5. Amare Y: Umbilical cord care in Ethiopia and implications for behavioral change: a qualitative study. BMC Int Health Hum Rights 2014, 14(1):12.

6. UN Commission on Life-Saving Commodities for Women and Children: Commisioners' Report [https://www.unfpa.org/sites/default/files/pubpdf/Final\%20UN\%20Commission\%20Report_14sept2012.pdf]

7. WHO Model List of Essential Medicines for Children [https://www.who.int/medicines/publications/essentialmedicines/en/]

8. Soofi S CS, Imdad A, Bhutto N, Ali N, Bhutta ZA.: Topical application of chlorhexidine to neonatal umbilical cords for prevention of omphalitis and neonatal mortality in a rural district of Pakistan: a community-based, cluster-randomised trial. Lancet (London, England) 2012, 17(9820):1029-1036.

9. Arifeen SE, Mullany LC, Shah R, Mannan I, Rahman SM, Talukder MR, Begum N, Al-Kabir A, Darmstadt GL, Santosham M et al: The effect of cord cleansing with chlorhexidine on neonatal mortality in rural Bangladesh: a community-based, cluster-randomised trial. Lancet (London, England) 2012, 379(9820):1022-1028.

10. Mullany LC, Darmstadt GL, Khatry SK, Katz J, LeClerq SC, Shrestha S, Adhikari R, Tielsch JM: Topical applications of chlorhexidine to the umbilical cord for prevention of omphalitis and neonatal mortality in southern Nepal: a community-based, cluster-randomised trial. Lancet (London, England) 2006, 367(9514):910-918.

11. WHO recommendations on postnatal care of the mother and newborn. [https://apps.who.int/iris/bitstream/handle/10665/97603/9789241506649_eng.pdf?sequence=1]

12. GSK and Save the Children partnership. [https://www.gsk.com/media/2756/save-the-childrenpartnership-progress-brochurepdf.pdf]

13. Muriuki A, Obare F, Ayieko B, Matanda D, Sisimwo K, Mdawida B: Health care providers' perspectives regarding the use of chlorhexidine gel for cord care in neonates in rural Kenya: implications for scaleup. BMC Health Serv Res 2017, 17(1):305-305.

14. Stewart D, Benitz W: Umbilical Cord Care in the Newborn Infant. Pediatrics 2016, 138(3):e20162149. 
15. Imdad A, Bautista RM, Senen KA, Uy ME, Mantaring JB, 3rd, Bhutta ZA: Umbilical cord antiseptics for preventing sepsis and death among newborns. The Cochrane database of systematic reviews 2013(5):Cd008635.

16. Sazawal S, Dhingra U, Ali SM, Dutta A, Deb S, Ame SM, Mkasha MH, Yadav A, Black RE: Efficacy of chlorhexidine application to umbilical cord on neonatal mortality in Pemba, Tanzania: a communitybased randomised controlled trial. The Lancet Global health 2016, 4(11):e837-e844.

17. Semrau KEA, Herlihy J, Grogan C, Musokotwane K, Yeboah-Antwi K, Mbewe R, Banda B, Mpamba C, Hamomba F, Pilingana $P$ et al: Effectiveness of $4 \%$ chlorhexidine umbilical cord care on neonatal mortality in Southern Province, Zambia (ZamCAT): a cluster-randomised controlled trial. The Lancet Global health 2016, 4(11):e827-e836.

18. Drug Safety Alert 133: Chlorhexidine and Eye Injury

[https://www.who.int/medicines/regulation/medicines-safety/alert133_chlorhexidine.pdf? ua $=1 \&$ ua $=1$ ]

19. The World Bank. Mortality rate, neonatal (per 1,000 live births) [https://data.worldbank.org/indicator/SH.DYN.NMRT]

20. Delivering Care for Newborns in Nairobi [https://kemri-wellcome.org/wpcontent/uploads/2019/05/DELIVERING-CARE-FOR-NEWBORNS-IN-NAIROBI.pdf]

21. Kenya Essential Medicines List [https://www.health.go.ke/wp-content/uploads/2020/03/KenyaEssential-Medicines-List-2019.pdf]

22. Golding N, Burstein R, Longbottom J, Browne AJ, Fullman N, Osgood-Zimmerman A, Earl L, Bhatt S, Cameron E, Casey DC et al: Mapping under-5 and neonatal mortality in Africa, 2000-15: a baseline analysis for the Sustainable Development Goals. Lancet (London, England) 2017, 390(10108):21712182.

23. Awiti JO: A multilevel analysis of prenatal care and birth weight in Kenya. Health Econ Rev 2014, 4(1):33.

24. Imdad A, Mullany, L.C., Baqui, A.H., Arifeen, S.E., Tielsch, J.M.,Khatry, S.K., Shah, R., Cousens, S., Black, R.E, Bhutta, Z.A.: The effect of umbilical cord cleansing with chlorhexidine on omphalitis and neonatal mortality in community settings in developing countries: a meta-analysis. BMC Public Healthvolume 2013, 13(S15).

25. WHO- CHOICE (Choosing interventions that are costeffective) [https://www.who.int/choice/costeffectiveness/en/]

26. Kenya Forecast: Consumer Price Index Growth [https://www.ceicdata.com/en/indicator/kenya/forecast-consumer-price-index-growth]

27. Basic pediatric protocols for ages up to 5 years. [http://publications.universalhealth2030.org/uploads/basic_paediatrics_protocols_feb_2016.pdf]

28. Pathologist Lancet Kenya Price List 2017 [http://lancet.co.ke/wp-content/uploads/2017/11/Pricelist-Updated-as-at-24-11-2017.pdf] 
29. Who Recommendations On Newborn Health Guidelines Approved By The Who Guidelines Review Committee [https://apps.who.int/iris/bitstream/handle/10665/259269/WHO-MCA-17.07-eng.pdf? sequence $=1$ ]

30. Kenya Demographic and Health Survey [https://dhsprogram.com/pubs/pdf/FR308/FR308.pdf]

31. From Research to Use; Saving Newborn Lives With Chlorhexidine for Umbilical Cord Care [https://path.azureedge.net/media/documents/DT_CHX_story_rpt.pdf]

32. Moon S, Mariat S, Kamae I, Pedersen HB: Defining the concept of fair pricing for medicines. BMJ 2020, 368:14726.

33. KEMSA LMIS Price List 2019 [http://www.kemsa.co.ke/wp-content/uploads/2019/06/KEMSA_LMISprice-list-June-2019.xIs]

34. Economic Survey 2018 [https://www.knbs.or.ke/download/economic-survey-2018/]

35. Burns PB, Rohrich RJ, Chung KC: The levels of evidence and their role in evidence-based medicine. Plast Reconstr Surg 2011, 128(1):305-310.

\section{Tables}

\section{Table 1: Key assumptions made in the CHX cost- consequence model.}

\begin{tabular}{|ll|}
\hline $\begin{array}{l}\text { Input } \\
\begin{array}{l}\text { Incidence rates } \\
\text { of omphalitis } \\
\text { with DCC }\end{array}\end{array}$ & $\begin{array}{l}\text { Assumptions } \\
\text { DCC, and the associated incidence rate of omphalitis, reflects the standard of care } \\
\text { data available from robust clinical trials limiting the comparison of CHX to DCC } \\
\text { only. Absolute cases of omphalitis avoided may be underestimated compared } \\
\text { with clinical practice. }\end{array}$ \\
\hline $\begin{array}{l}\text { Comparative } \\
\text { efficacy: relative } \\
\text { risk of } \\
\text { omphalitis }\end{array}$ & $\begin{array}{l}\text { The relative risk of omphalitis for CHX versus DCC in the base case is assumed } \\
\text { based on data from the Cochrane review for the least severe category of } \\
\text { omphalitis. }\end{array}$ \\
$\begin{array}{l}\text { Comparative } \\
\text { efficacy: } \\
\text { mortality }\end{array}$ & $\begin{array}{l}\text { Not included in the model. Therefore, the effect of CHX is only applied to rates of } \\
\text { omphalitis. }\end{array}$ \\
$\begin{array}{l}\text { Medications to } \\
\text { treat omphalitis }\end{array}$ & $\begin{array}{l}\text { Assumed to predominantly follow clinical opinion. Clinical practice may differ } \\
\text { from guideline recommendations. }\end{array}$ \\
$\begin{array}{l}\text { Productivity } \\
\text { loss }\end{array}$ & $\begin{array}{l}\text { Calculated based on the average salary in Kenya and therefore average cost of } \\
\text { time lost. }\end{array}$ \\
\hline
\end{tabular}

$\mathrm{CHX}$, chlorohexidine treatment; DCC, dry cord care. 


\section{Table 2: Model-predicted direct and indirect cost summary for CHX versus DCC for a birth cohort of 500,000 for 1 year.}

\begin{tabular}{|c|c|c|c|}
\hline & DCC (USD) & CHX (USD) & Difference* \\
\hline \multicolumn{4}{|l|}{ Omphalitis treatment } \\
\hline Medication cost & 147,121 & 107,398 & $-39,723$ \\
\hline Hospitalisation costs & $1,479,943$ & $1,080,358$ & $-399,585$ \\
\hline Outpatient costs & 108,289 & 79,051 & $-29,238$ \\
\hline Non-medication costs & 444,433 & 324,436 & $-119,997$ \\
\hline TOTAL direct costs & $2,179,787$ & $1,591,244$ & $-588,542$ \\
\hline Salary loss due to child with omphalitis & $7,879,007$ & $5,751,675$ & $-2,127,332$ \\
\hline Total direct and indirect costs & $10,058,793$ & $7,342,919$ & $-2,715,874$ \\
\hline
\end{tabular}

CHX, chlorhexidine; DCC, dry cord care; USD, US dollar.

*Negative value indicates a cost saving associated with $\mathrm{CHX}$ compared with DCC.

\section{Table 3: Model-predicted omphalitis-related resource use associated with $\mathrm{CHX}$ and DCC for a birth cohort of 500,000 for 1 year.}

\begin{tabular}{|llll|}
\hline & DCC & CHX & Difference \\
\hline Workdays lost & 423,874 & 309,428 & $-114,446$ \\
\hline Bed days & 161,072 & 117,583 & $-43,489$ \\
\hline Outpatient visits & 48,322 & 35,275 & $-13,047$ \\
\hline
\end{tabular}

CHX, chlorhexidine; DCC, dry cord care.

\section{Figures}




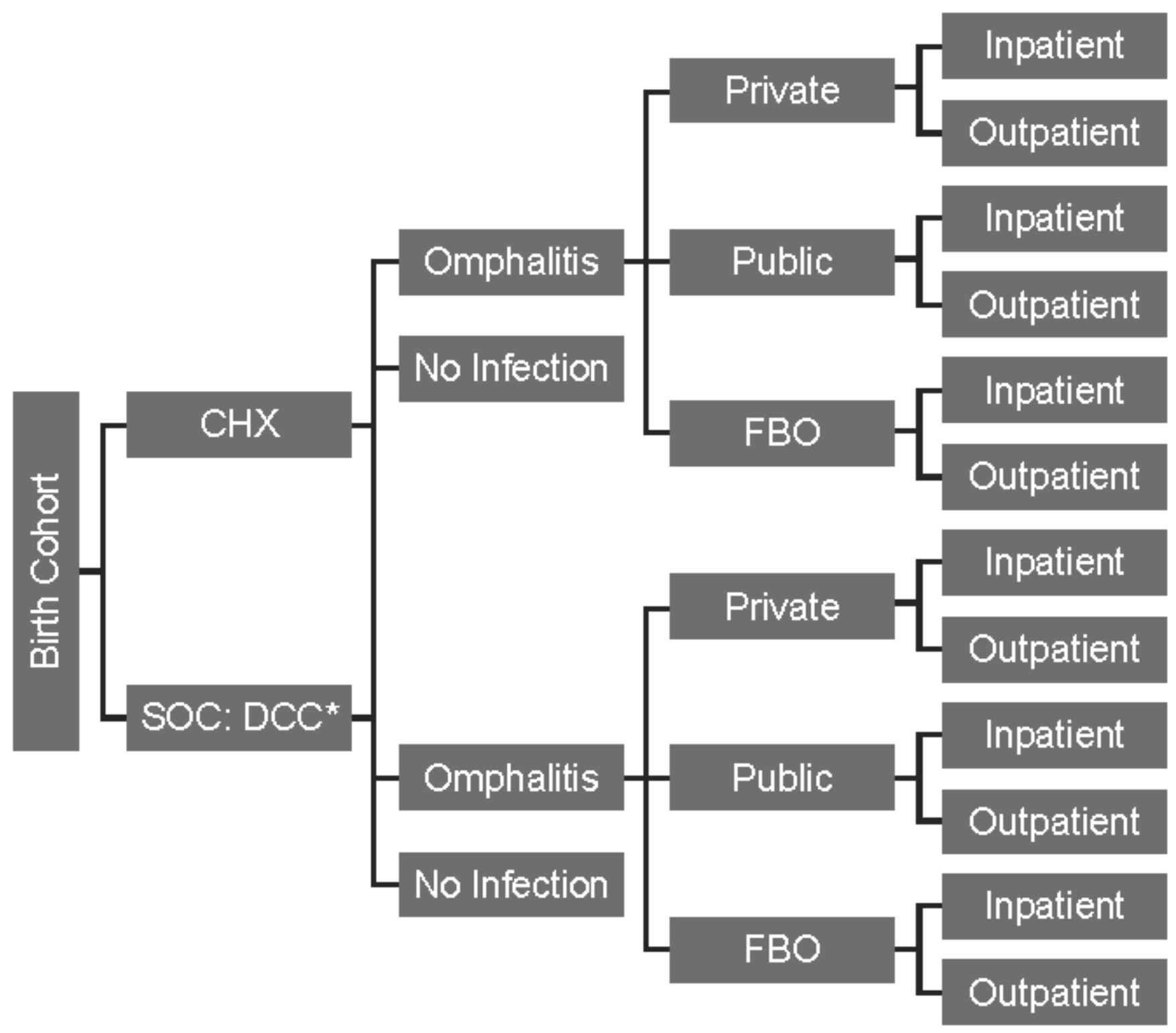

Figure 1

Cost-consequence model design. *Although DCC represented SOC in this model, it is not viewed as being realistically representative of the SOC in Kenya, where harmful substances such as methylated spirits, ash or saliva, are often used [3-5]. CHX, chlorhexidine; DCC, dry cord care; FBO, faith-based organisation; SOC, standard of care. 


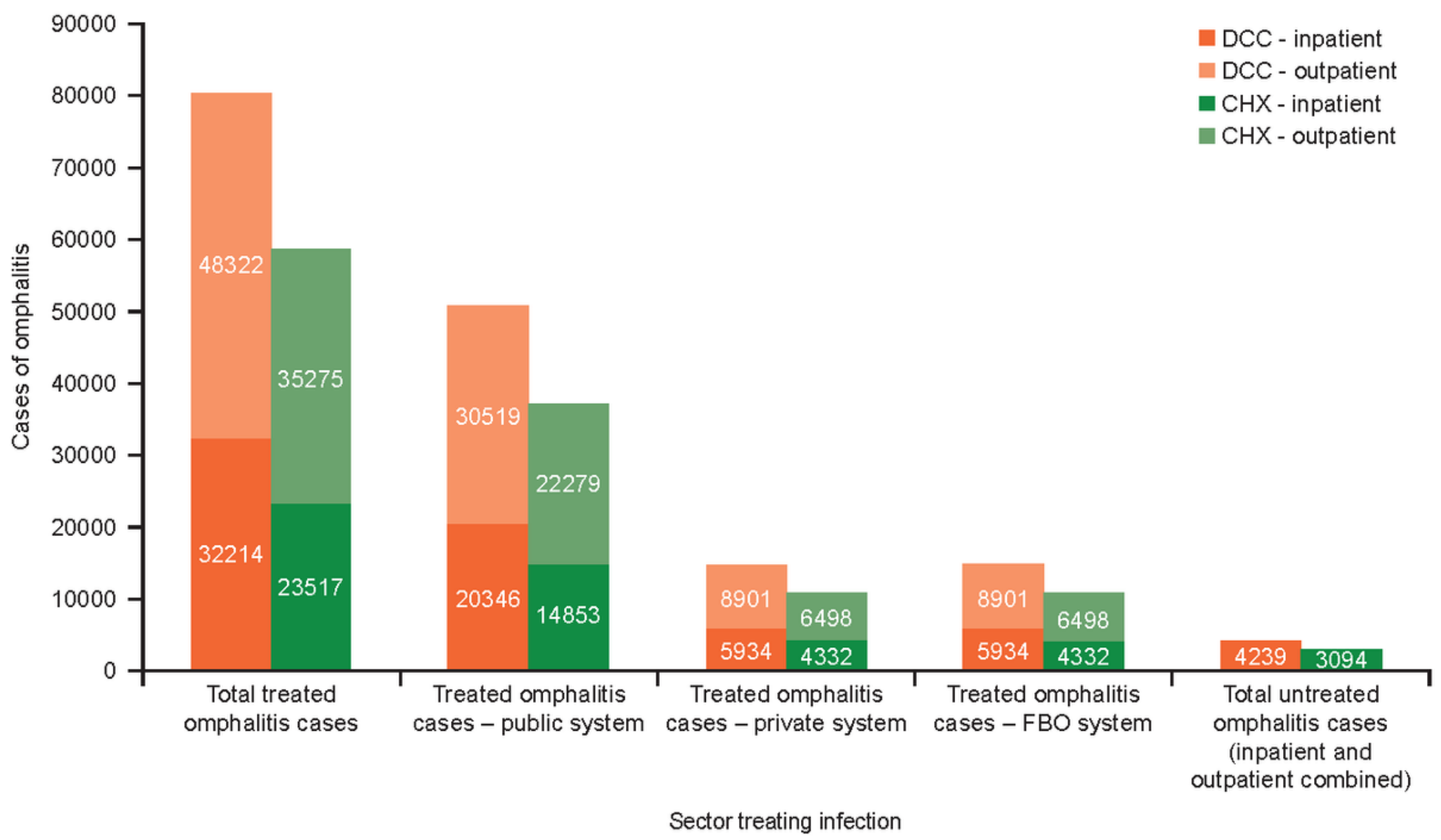

Figure 2

Model-predicted cases of omphalitis by sector treating the omphalitis infection for a birth cohort of 500,000 for 1 year. CHX, chlorhexidine; DCC, dry cord care; FBO, faith-based organisation. 

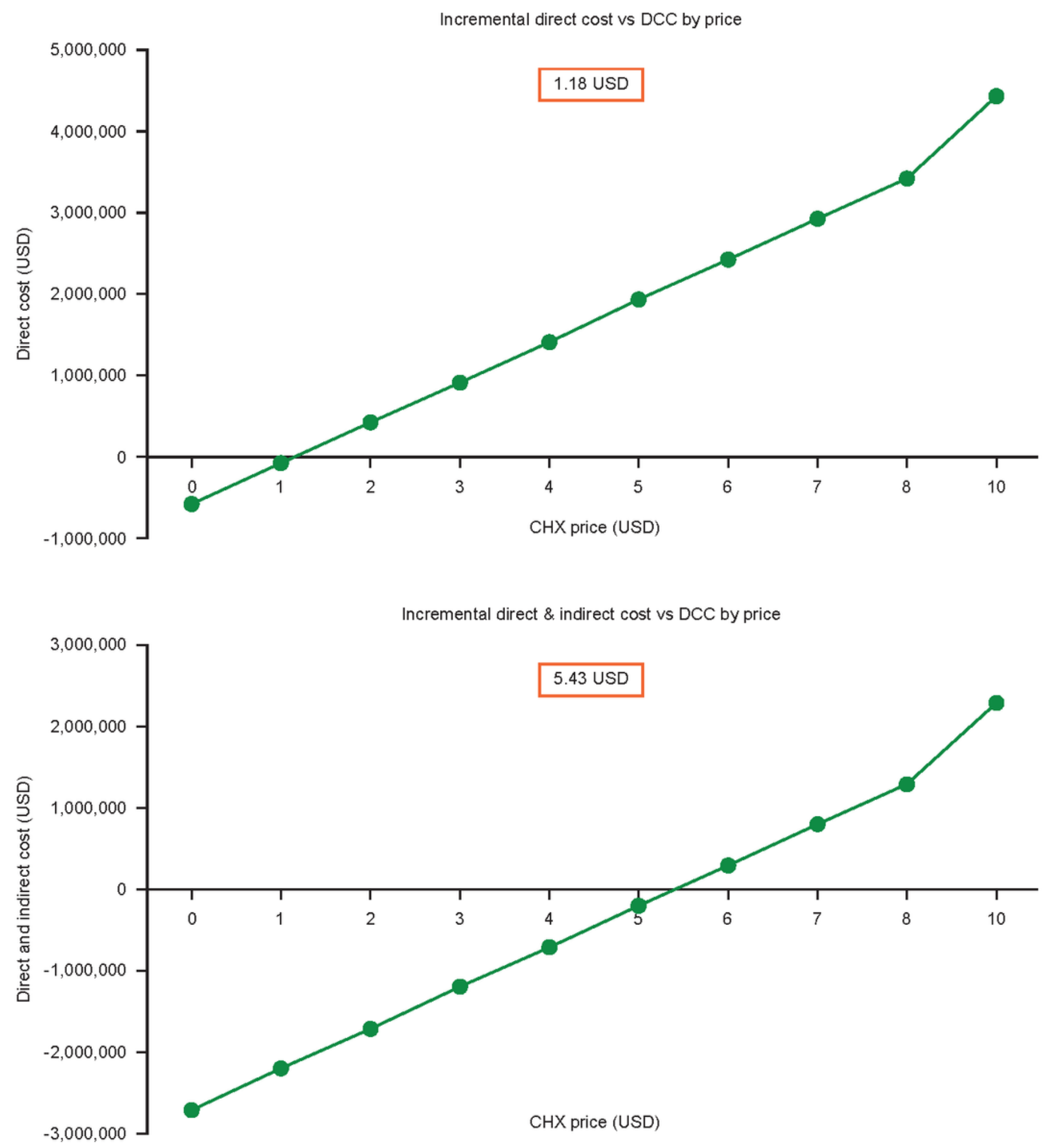

Figure 3

Breakeven analysis of direct cost and a combination of direct and indirect costs of $\mathrm{CHX}$ compared with DCC. CHX, chlorhexidine; DCC, dry cord care; USD, US dollar. 


\section{Incremental costs}

1 Relative risk omphalitis: $\mathrm{CH}$ X vs DCC $(0.73,0.58,0.88)$

2 Wastage with tablets (omphalitis treatment) (per patient, daily, none)

3 Omphalitis incidence with DCC $(0.170,0.136,0.203)$

4 Inpatient treatment (\%): Public $(40.0 \%, 32.0 \%, 48.0 \%)$

5 Inpatient length of stay (days): Public $(5.0,4.0 .6 .0)$

6 Inpatient length of stay (days): Private $(5.0,4.0,6.0)$

7 Inpatient treatment (\%): Private $(40.0 \%, 32.0 \%, 48.0 \%)$

8 Inpatient treatment (\%): FBO $(40.0 \%, 32.0 \%, 48.0 \%)$

9 Inpatient length of stay (days): FBO $(5.0,4.0,6.0)$

10 Proportion of patients treated in private facilities $(17.5 \%, 14.0 \%, 21.0 \%)$

11 Average weight $(\mathrm{kg})$ $(3.30,2.64,3.96)$

12 Oral penicillin price per pack (KSH) $(360,288,432)$

13 Wastage with vials (omphalitis treatment) (PerPatient, Daily, None)

14 Item cost haemogram (KSH): Private $(1299,1039,1559)$

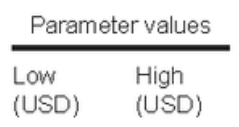
Breakeven Breakeven
price: Low price: High (USD) (USD)

$\begin{array}{llll}-906.791 & -270.294 & 1.81 & 0.54\end{array}$

$\begin{array}{llll}-945.671 & -585.518 & 1.89 & 1.17\end{array}$

$\begin{array}{llll}-470,834 & -706,251 & 0.94 & 1.41\end{array}$

$\begin{array}{llll}-541,106 & -635.978 & 1.08 & 1.27\end{array}$

$\begin{array}{llll}-541,885 & -635,200 & 1.08 & 1.27\end{array}$

$\begin{array}{llll}-570.998 & -606.086 & 1.14 & 1.21\end{array}$

$\begin{array}{llll}-571.030 & -606.055 & 1.14 & 1.21\end{array}$

$\begin{array}{llll}-572,812 & -604,272 & 1.15 & 1.21\end{array}$

$\begin{array}{llll}-572,827 & -604,258 & 1.15 & 1.21\end{array}$

$\begin{array}{llll}-574,700 & -602,384 & 1.15 & 1.20\end{array}$

$\begin{array}{llll}-579,528 & -596,866 & 1.16 & 1.19\end{array}$

$\begin{array}{llll}-582,331 & -594.753 & 1.16 & 1.19\end{array}$

$\begin{array}{llll}-598.204 & -586,320 & 1.20 & 1.17\end{array}$

$-574.781 \quad-585,790 \quad 1.15$

1.17

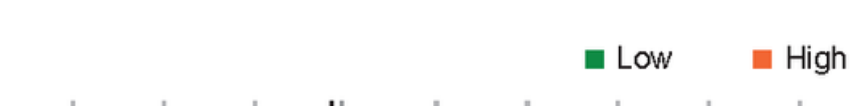

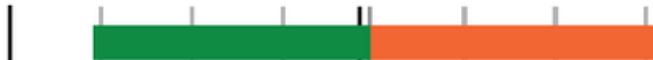




\section{Incremental costs}

\begin{tabular}{ll}
\multicolumn{2}{c}{ Parametervalues } \\
\hline Low & $\begin{array}{l}\text { High } \\
\text { (USD) }\end{array}$ \\
(USD)
\end{tabular}

Breakeven Breakeven

price: Low price: High

(USD) (USD) (USD) (USD)

1 Relative risk omphalitis: $\mathrm{CHX}$ vs DCC $(0.73,0.58,0.88)$

$\begin{array}{lll}-4,184,458 & -1,247,290 \quad 837\end{array}$

(USD)

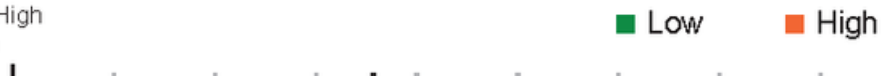

2 Average work days lost per case $(5.0,1.0,6.0)$

3 Omphalitis incidence with DDC $(0.170,0.136,0.203)$

$\begin{array}{llll}-1,014,009 & -3,141,341 & 2.03 & 6.28\end{array}$

$-2,172,699 \quad-3,259,049 \quad 4.35 \quad 6.52$

$-2,290,408 \quad-3,141,341 \quad 4.58 \quad 6.28$

Average annual income (KSH) (684097, 547278, 820916)

5 Wastage with tablets (omphalitis treatment) $-3,073,003 \quad-2,712,850 \quad 6.15 \quad 5.43$ (per patient, daily, none)

6 Inpatient treatment (\%): Public $(40.0 \%, 32.0 \%, 48.0 \%)$

$-2,668,438 \quad-2,763,310 \quad 5.34 \quad 5.53$

7 Inpatient length of stay (days): Public $(5.0,4.0,6.0)$

$\begin{array}{llll}-2,669,217 & -2,762,532 & 5.34 & 5.53\end{array}$

8 Inpatient length of stay (days): Private $(5.0,4.0,6.0)$

9 Inpatient treatment (\%): Private $(40.0 \%, 32.0 \%, 48.0 \%)$

10 Inpatient treatment (\%): FBO $(40.0 \%, 32.0 \%, 48.0 \%)$

11 inpatient length of stay (days): FBO $(5.0,4.0,6.0)$

12 Proportion of patients treated in private facilities (\%)

$(17.5 \%, 14.0 \%, 21.0 \%)$

13 Average weight $(\mathrm{kg})$ $(3.30,2.64,3.96)$

14 Oral penicillin price per pack (KSH) $(360,288,432)$

$\begin{array}{llll}-2,698,330 & -2,733,418 & 5.40 & 5.47\end{array}$

$\begin{array}{llll}-2,698,362 & -2,733,387 & 5.40 & 5.47\end{array}$

$\begin{array}{llll}-2,700,144 & -2,731,604 & 5.40 & 5.46\end{array}$

$\begin{array}{llll}-2,700,159 & -2,731,590 & 5.40 & 5.46\end{array}$

$\begin{array}{llll}-2,702,032 & -2,729,716 & 5.40 & 5.46\end{array}$

$\begin{array}{llll}-2,706,860 & -2,724,198 & 5.41 & 5.45\end{array}$

$-2,709,663 \quad-2,722,085 \quad 5,42$

5.44

\section{Figure 5}

One-way sensitivity analysis of the impact that changes in direct and indirect costs will have on the economic evaluation output. CHX, chlorhexidine treatment; DCC, dry cord care; FBO, faith-based organisation; $\mathrm{KSH}$, Kenyan shilling; USD, US dollar.

\section{Supplementary Files}

This is a list of supplementary files associated with this preprint. Click to download.

- CHXcostconsequencemodelSupplementaryMaterial.docx 